\title{
Blood pressure in 3-year-old girls associates inversely with umbilical cord serum 25-hydroxyvitamin D: an Odense Child Cohort study
}

\author{
Søs Dragsbæk Larsen', Christine Dalgård 1,2, Mathilde Egelund Christensen 1, Sine Lykkedegn³, \\ Louise Bjørkholt Andersen ${ }^{1,4}$, Marianne Andersen ${ }^{1,5}$, Dorte Glintborg ${ }^{5}$ and Henrik Thybo Christesen ${ }^{1,3}$ \\ ${ }^{1}$ Department of Clinical Research, Faculty of Health Sciences, University of Southern Denmark, Odense, Denmark \\ ${ }^{2}$ Department of Public Health, Environmental Medicine, University of Southern Denmark, Odense, Denmark \\ ${ }^{3}$ Hans Christian Andersen Children's Hospital, Odense University Hospital, Odense, Denmark \\ ${ }^{4}$ Department of Obstetrics and Gynecology, Herlev Hospital, Copenhagen, Denmark \\ ${ }^{5}$ Department of Medical Endocrinology, Odense University Hospital, Odense, Denmark \\ Correspondence should be addressed to M Andersen: Marianne.andersen1@rsyd.dk
}

\begin{abstract}
Background: Low foetal vitamin D status may be associated with higher blood pressure (BP) in later life.

Objective: To examine whether serum 25-hydroxyvitamin $\mathrm{D}_{2+3}$ (s-25OHD) in cord and pregnancy associates with systolic and diastolic BP (SBP; DBP) in children up to 3 years of age. Design: Prospective, population-based cohort study. Methods: We included 1594 singletons from the Odense Child Cohort with available cord s-25OHD and BP data at median age 3.7 months (48\% girls), 18.9 months (44\% girls) or 3 years (48\% girls). Maternal s-25OHD was also assessed at gestational ages 12 and 29 weeks. Multiple regression models were stratified by sex a priori and adjusted for maternal educational level, season of birth and child height, weight and age.

Results: In 3-year-old girls, SBP decreased with $-0.7 \mathrm{mmHg}(95 \% \mathrm{Cl}-1.1 ;-0.3, P=0.001)$ and DBP with $-0.4 \mathrm{mmHg}(95 \% \mathrm{Cl}-0.7 ;-0.1, P=0.016)$ for every $10 \mathrm{nmol} / \mathrm{L}$ increase in cord s-25OHD in adjusted analyses. Moreover, the adjusted odds of having SBP >90th percentile were reduced by $30 \%$ for every $10 \mathrm{nmol} / \mathrm{L}$ increase in cord $\mathrm{s}-25 \mathrm{OHD}(P=0.004)$ and by $64 \%$ for cord s-25OHD above the median $45.1 \mathrm{nmol} / \mathrm{L}(P=0.02)$. Similar findings were observed between pregnancy s-25OHD and 3-year SBP, cord S-25OHD and SBP at 18.9 months, and cord s-25OHD and DBP at 3 years. No consistent associations were observed between S-25OHD and BP in boys.

Conclusion: Cord s-25OHD was inversely associated with SBP and DBP in young girls, but not in boys. Higher vitamin D status in foetal life may modulate BP in young girls. The sex difference remains unexplained.
\end{abstract}

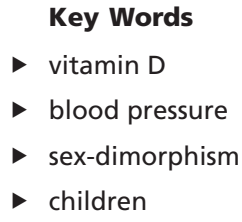

Endocrine Connections (2018) 7, 1236-1244

\section{Introduction}

High blood pressure (BP) increases cardiovascular risk and constitutes one of the primary modifiable risk factors for cardiovascular disease (1). Elevated BP in childhood increases the risk of prehypertension and hypertension in adulthood $(2,3)$, making it essential to prevent high BP in children. Identification of modifiable, early risk factors

$$
\begin{array}{lr}
\text { https://ec.bioscientifica.com } & \text { ○ } 2018 \text { The authors } \\
\text { https://doi.org/10.1530/EC-18-0308 } & \text { Published by Bioscientifica Ltd }
\end{array}
$$

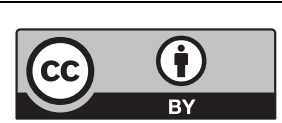


is a key in designing initiatives preventing future cardiovascular events. Recently, hypovitaminosis D, defined as serum 25-hydroxyvitamin D (s-25OHD) $<50 \mathrm{nmol} / \mathrm{L}$, was suggested to be a risk factor for cardiovascular events (4). The potential cardioprotective properties of vitamin D stem from its biological actions including its ability to inhibit vascular smooth muscle cell proliferation and potentially regulate the renin-angiotensin system (RAS) $(5,6,7)$. An inverse relationship between $\mathrm{BP}$ and vitamin $\mathrm{D}$ levels in both children and adults is observed in some, but not all, studies $(5,8,9)$.

Hypovitaminosis D during pregnancy is a common global phenomenon $(10,11)$. Increasing evidence suggests that insufficient vitamin D status during foetal life may increase the risk of several adverse health outcomes in later life, although the mechanisms remain to be fully elucidated (12).

Adverse events in utero and in early life may have programming effects on BP and cardiovascular health in later life (13). Foetal vitamin D status depends solely on the 25OHD concentrations of the mother (10). Studies examining the association between maternal 25OHD concentrations during pregnancy and BP and other cardiovascular disease risk factors in the offspring have shown inconsistent results $(14,15,16)$. However, an inverse association between maternal 25OHD in pregnancy and offspring systolic BP at age 9.9 years has been observed, suggesting a possible programming effect of foetal vitamin D status on child BP (14). Moreover, the inverse association between maternal s-25OHD in pregnancy and offspring BP at age 20 years was seen in females only (17), which indicates a possible sex-specific effect.

Our objective was to investigate whether s-25OHD in cord blood and during pregnancy (median gestational age 12 and 29 weeks) was associated with offspring systolic and diastolic blood pressures (SBP/DBP) in children up to about 3 years of age. The study derived from Odense Child Cohort (OCC), a large prospective birth cohort, which has previously been described in detail (18).

\section{Subjects and methods}

\section{Study population}

Participants were included from Odense Child Cohort (OCC), an on-going prospective, observational cohort consisting of mothers and their children. Inclusion criteria of OCC were residence in the Municipality of Odense and newly discovered pregnancy in the period of 1/1/2010-31/12/2012. Exclusion criteria were migration

$\begin{array}{lr}\text { https://ec.bioscientifica.com } & \text { ○ } 2018 \text { The authors } \\ \text { https://doi.org/10.1530/EC-18-0308 } & \text { Published by Bioscientifica Ltd }\end{array}$

out of the municipality, miscarriage and stillbirth, resulting in 2549 active mother-children dyads. A more detailed description of the cohort has been published previously (18). Further exclusion criteria were multiple births, unavailable cord s-25OHD and missing measurements of BP at infant follow-up (Fig. 1).

We included 1594 children with measurements of cord s-25OHD and BP at a median and 25th-75th percentile [Q1; Q3] age of 3.7 [3.1; 4.4] months, 18.9 [18.3; 19.5] months and 36.0 [35.8; 36.6] months, respectively. SBP and DBP were measured in 1064 children (67\%; 508 girls, 556 boys) at 3.7 months, 771 (48\%; 341 girls, 430 boys) at 18.9 months and 1110 (70\%; 530 girls, 580 boys) at 3 years.

\section{Exposure}

Blood samples were drawn for analysis of s-25OHD from the umbilical cord and twice during pregnancy (median [Q1; Q3] gestational age 12 [10; 15] and 29 [28; 30] weeks). All samples were immediately processed and stored at $-80^{\circ} \mathrm{C}$ until analysis. Concentrations of $\mathrm{s}-25 \mathrm{OHD}_{2+3}$ were assessed using liquid chromatography-tandem mass spectrometry (LC-MS/MS) as previously described, calibrated against National Institute of Standards and Technology, Standard Reference Material 972 with a CV of $\mathrm{s}-25 \mathrm{OHD}_{2+3}<7 \%$ (11). Cord $\mathrm{s}-25 \mathrm{OHD}$ was chosen as primary exposure. Maternal pregnancy blood samples were divided into early pregnancy (before week $20+0$ days) and late pregnancy (week $20+0$ onwards).

\section{Outcomes}

Assessments of BP were performed at the age of 3 months, 18 months and 3 years by trained study staff. BP was measured in the left arm by a Welch Allyn device using a cuff of appropriate size. At 3 months of age, BP was measured with the child resting in a supine position; and at 18 months and 3 years, resting in the sitting position. Measurement of SBP at the age of 3 years was considered the primary outcome.

\section{Covariates}

Maternal characteristics included the following selfreported data extracted from questionnaires: maternal skin tone on a modified Fitzpatrick's Scale (19) (fair, darker white, brown or dark skin), maternal education (lower, intermediate or higher level), maternal sun exposure during pregnancy (never/rarely, sometimes,

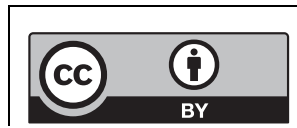




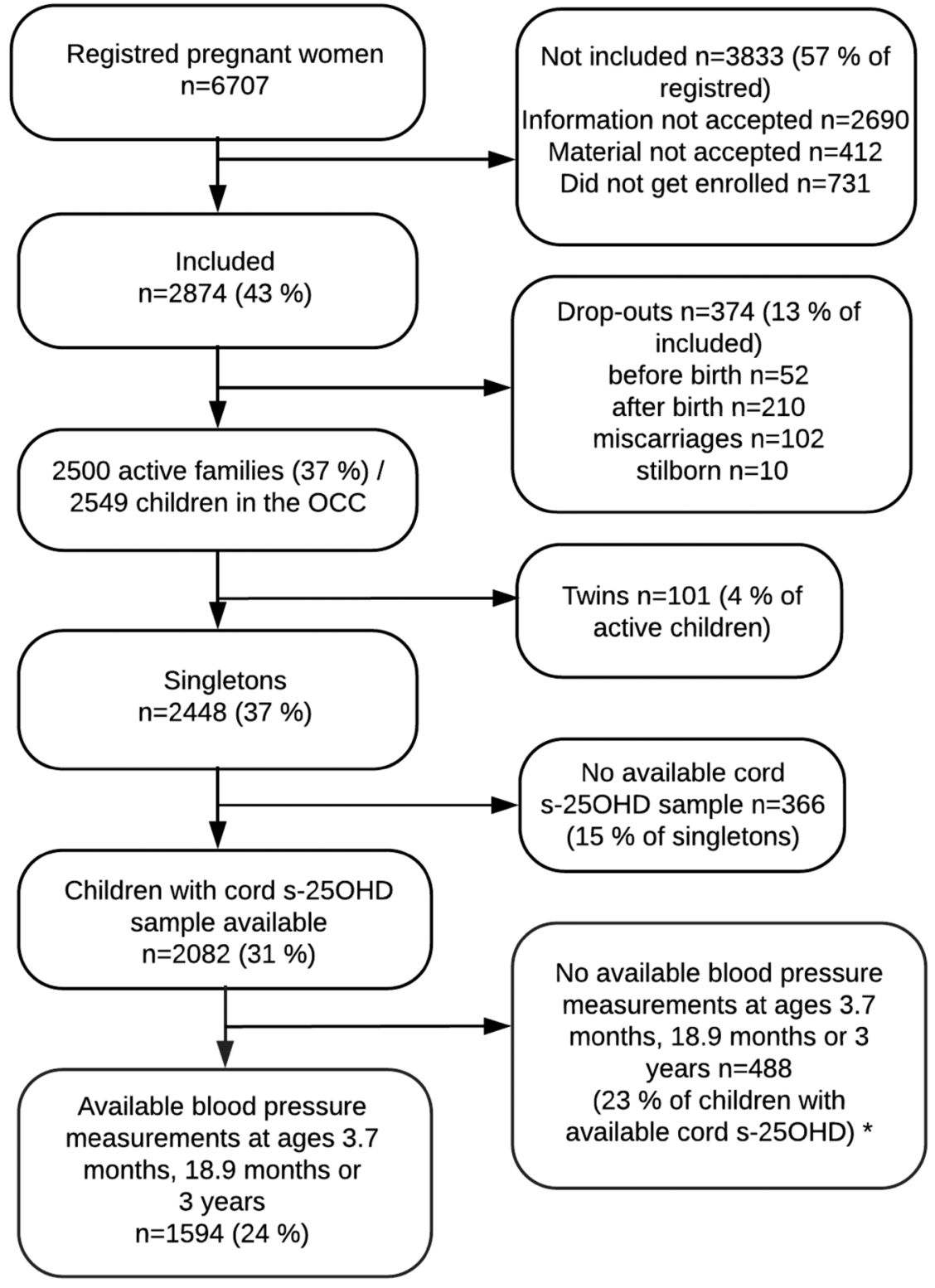

Figure 1

Flowchart of the study population. OCC, Odense Child Cohort; s-25OHD, serum 25-hydroxyvitamin $D_{2+3}$. *Five measurements of systolic blood pressure and four of diastolic blood pressure were regarded an error of data entry and therefore coded as missing. often, or most of the time), gestational weight gain and vitamin $\mathrm{D}$ supplementation during pregnancy $(<10 \mu \mathrm{g} /$ day or $\geq 10 \mu \mathrm{g} /$ day). Data on maternal country of birth (western/non-western) were provided by the Municipality of Odense. Information on parity, smoking during pregnancy (smokers/non-smokers) and maternal pre-gestational BMI was extracted from self-reported data at the first antenatal visit. Maternal age was calculated at time of birth. Characteristics of the children including sex and gestational age (days) at birth were derived from medical files, while data of infant feeding (breastfed/ non-breastfed, number of weeks of breastfeeding) and use of vitamin D supplementation ( $\mu$ g/day) were selfreported and extracted from questionnaires. Season of blood sampling was defined as either May-October or November-April, representing the seasons of high and low s-25OHD, respectively (11). Child weight was measured without clothing using a digital weight, and a stadiometer was used for the measures of height. Length was measured in a supine position at the age of 3 and 18 months; standing height at 3 years.

\section{Statistical analysis}

Distribution of data was evaluated visually in qq-plots and presented as mean and standard deviations (SD) or median [Q1; Q3] where appropriate. Testing for differences between quartiles of cord s-25OHD was performed by

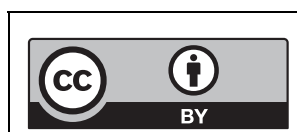

This work is licensed under a Creative Commons Attribution 4.0 International License. 
ANOVA or Kruskal-Wallis test for continuous variables, and chi-square test was applied for categorical variables.

Multiple linear regression analyses were applied to test the associations between cord s-25OHD and BP. Moreover, the association of cord s-25OHD with BP $>90$ th percentile was tested in multiple logistic regression analyses. Concentrations of cord s-25OHD were used as a continuous variable or categorised according to either median or quartiles. We conducted test for trend by evaluating the significance of s-25OHD grouped by quartiles. In addition, multiple linear regression models were performed with maternal s-25OHD in early and late pregnancy, respectively, as secondary exposure variables. Covariates were included in the multiple regression models if they were significantly related to BP, or if they were consistently used throughout the literature, and they were retained as potential confounders if they changed the main estimate (association between cord s-25OHD and BP) by $>10 \%$. The models were stratified by child sex a priori.

Model assumptions were checked for every linear model by evaluating the distribution of the studentized residuals in a qq-plot. Furthermore, logistic regression models were tested by Pearson goodness-of-fit test. Analyses were conducted using STATA 14.0 software (StataCorp). A significance level at $P<0.05$ was chosen using two-sided tests.

The study was powered to detect a true change in SBP of $0.3 \mathrm{mmHg}$ for every $10 \mathrm{nmol} / \mathrm{L}$ change in cord s-25OHD, given $n=1110$, alfa $=0.05$, beta $=0.80$, cord $s-250 H D$ SD $22 \mathrm{nmol} / \mathrm{L}$ and $\mathrm{SBP} \mathrm{SD}=8$.

\section{Ethics}

The women provided written informed consent to participate in the study approved by the Regional Scientific Ethical Committee for Southern Denmark, no S-20090130 and conducted in accordance with the Helsinki Declaration II. The study was also approved by the Danish Data protection Board, application no. $13 / 14088$.

\section{Results}

\section{Participants and variables}

In the 1594 included children, median cord s-25OHD was 45.1 [30.6, 60.2] $\mathrm{nmol} / \mathrm{L}$, and $41.7 \%$ of the study population had levels of s-25OHD between
(๑) 2018 The authors Published by Bioscientifica Ltd
25.0 and $49.9 \mathrm{nmol} / \mathrm{L}$ (denoted vitamin D insufficiency), while $16.6 \%$ had levels below $25.0 \mathrm{nmol} / \mathrm{L}$ (denoted vitamin D deficiency). Characteristics of mothers and offspring according to quartiles of cord s-25OHD are shown in Table 1. Children with levels of cord s-25OHD in Q1 $(<30.6 \mathrm{nmol} / \mathrm{L})$ had mothers who were more often overweight or obese, smokers, of non-western ethnicity, and with higher parity, less sun exposure and lower vitamin D supplementation level compared to mothers of children with levels in the other quartiles, $P<0.01$ for all. Children with cord s-25OHD $<30.6 \mathrm{nmol} / \mathrm{L}$ had higher SBP, received less vitamin D supplementation per day and were more often born in the winter-spring period, $P<0.05$ for all.

The mean SBP/DBP at 3.7, 18.9 and 36 months were $102 / 61,100 / 63$ and $100 / 63 \mathrm{mmHg}$, respectively. For details, see Supplementary Table 1 (see section on supplementary data given at the end of this article).

\section{Cord s-250HD and blood pressure association}

Univariate linear regression analyses showed highly significant inverse associations between cord s-25OHD and SBP in 3-year-old girls (Table 2). Unadjusted associations between cord s-25OHD above vs below median and SBP in 3-year-old girls and DBP in 18.9 months and 3-yearold girls were also observed. Additionally, an inverse association between cord s-25OHD (continuous and above vs below median) and SBP >90th percentile in 3-year-old girls was found.

Highly significant inverse associations were observed between cord s-25OHD and SBP and DBP in 3 -year-old girls in multiple linear regression model adjusted for maternal educational level, season of birth and child height, weight and age (Table 3 ). The girls with cord s-25OHD levels above median had $2.5 \mathrm{mmHg}$ lower SBP $(P=0.002)$ and $1.7 \mathrm{mmHg}$ lower DBP $(P=0.009)$ than the girls with levels below the median. Significant trends toward lower SBP $(P=0.002)$ and DBP $(P=0.019)$ were observed with increasing cord s-25OHD quartiles (Fig. 2).

The adjusted odds of having SBP >90th percentile were reduced by $30 \%$ for every $10 \mathrm{nmol} / \mathrm{L}$ increase in cord s-25OHD at 18.9 months and 3 years in girls and by $20 \%$ for DBP in 3-year-old girls (Table 3). Likewise, the adjusted odds for having SBP >90th percentile were reduced by two thirds for 18.9-months- and 3-years-old girls with cord s-25OHD above the median of $45.1 \mathrm{nmol} / \mathrm{L}$. No associations between s-25OHD and BP were detected at the age of 3.7 months.

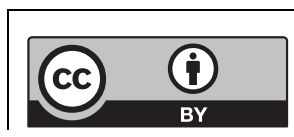

This work is licensed under a Creative Commons Attribution 4.0 International License. 
Table 1 Characteristics of the study population according to quartiles of cord s-25OHD.

\begin{tabular}{|c|c|c|c|c|c|c|}
\hline & & & Quartiles of coro & 250HD (nmol/L) & & \\
\hline & $\mathbf{N}$ & $<30.6$ & $30.6-45.1$ & $45.2-60.2$ & $>60.2$ & P Value \\
\hline Maternal characteristics & & & & & & \\
\hline Gestational weight gain $(\mathrm{kg})$ & 675 & $15.0(5.9)^{\mathrm{a}}$ & $14.8(5.6)$ & $15.0(5.5)$ & $14.2(5.2)$ & 0.512 \\
\hline Maternal age (years) & 1594 & $30.1(4.5)$ & $30.4(4.4)$ & $30.5(4.5)$ & $30.3(4.4)$ & 0.620 \\
\hline Pregestational BMI $\left(\mathrm{kg} / \mathrm{m}^{2}, \%\right)$ & & & & & & $<0.001$ \\
\hline Underweight: $<18$ & 51 & 2.8 & 1.3 & 3.8 & 5.0 & \\
\hline Normal weight: 18-24.9 & 1000 & 54.0 & 68.7 & 62.8 & 65.4 & \\
\hline Obese: $30-35$ & 120 & 11.3 & 5.3 & 24.6 & 6.8 & \\
\hline Severely obese: >35 & 53 & 6.3 & 3.5 & 6.8 & 1.5 & \\
\hline Smoker $(\%)$ & & & & & & 0.005 \\
\hline Yes & 67 & 7.3 & 3.0 & 3.5 & 3.0 & \\
\hline No & 1527 & 92.7 & 97.0 & 96.5 & 97.0 & \\
\hline Educational level (\%) & & & & & & 0.595 \\
\hline Low & 188 & 16.6 & 15.6 & 13.3 & 16.1 & \\
\hline Intermediate & 741 & 58.8 & 58.3 & 61.5 & 63.6 & \\
\hline Ethnicity (\%) & & & & & & $<0.001$ \\
\hline Western & 1522 & 90.7 & 96.0 & 96.7 & 98.5 & \\
\hline Non-western & 72 & 9.3 & 4.0 & 3.3 & 1.5 & \\
\hline Skin-type (\%) & & & & & & 0.094 \\
\hline I/II White & 239 & 23.0 & 20.1 & 17.9 & 16.3 & \\
\hline III Darker white & 732 & 54.1 & 61.4 & 63.6 & 57.8 & \\
\hline IV Brown & 248 & 21.0 & 17.3 & 17.6 & 25.2 & \\
\hline V/VI Dark brown & 15 & 1.9 & 1.2 & 0.9 & 0.7 & \\
\hline Parity (\%) & & & & & & 0.002 \\
\hline 1 & 882 & 45.7 & 57.4 & 59.6 & 58.7 & \\
\hline 2 & 542 & 40.5 & 32.1 & 30.1 & 32.6 & \\
\hline$\geq 3$ & 170 & 13.8 & 10.5 & 9.6 & 8.8 & \\
\hline Vitamin D supplementation (\%) & & & & & & $<0.001$ \\
\hline$<10 \mu \mathrm{g} / \mathrm{day}$ & 131 & 24.4 & 11.0 & 11.1 & 8.3 & \\
\hline$\geq 10 \mu \mathrm{g} / \mathrm{day}$ & 834 & 75.7 & 89.0 & 88.9 & 91.7 & \\
\hline Maternal sun exposure (\%) & & & & & & 0.007 \\
\hline Never/rarely & 24 & 2.6 & 2.2 & 1.6 & 1.4 & \\
\hline Most of the time & 219 & 19.4 & 13.2 & 18.8 & 19.9 & \\
\hline Paternal characteristics & & & & & & \\
\hline Paternal BMI $\left(\mathrm{kg} / \mathrm{m}^{2}, \%\right)$ * & & & & & & 0.518 \\
\hline $\mathrm{BMI}<24.9$ & 513 & 48.0 & 51.8 & 47.4 & 55.1 & \\
\hline Overweight: $25-29.9$ & 397 & 38.6 & 38.9 & 41.4 & 37.1 & \\
\hline Obese: $30-35$ & 86 & 10.6 & 7.8 & 9.7 & 5.7 & \\
\hline Severely obese: $>35$ & 20 & 2.9 & 1.6 & 1.5 & 2.0 & \\
\hline Child characteristics & & & & & & \\
\hline Height 3 years (months) & 1099 & $0.97(0.04)$ & $0.97(0.03)$ & $0.97(0.04)$ & $0.97(0.04)$ & 0.220 \\
\hline Weight 3 years $(\mathrm{kg})$ & 1105 & $15.0[13.8,16.0]^{\mathrm{b}}$ & $14.8[13.6,15.9]$ & $14.9[13.8,16.0]$ & $14.7[13.6,15.7]$ & 0.264 \\
\hline BMI 3 years $\left(\mathrm{kg} / \mathrm{m}^{2}\right)$ & 1084 & $15.8[15.1,16.5]$ & $15.7[15.0,16.5]$ & $15.8[15.1,16.5]$ & $15.7[15.1,16.4]$ & 0.674 \\
\hline SBP 3 years $(\mathrm{mmHg})$ & 1110 & $101(8)$ & $100(7)$ & $100(7)$ & $99(7)$ & 0.018 \\
\hline DBP 3 years $(\mathrm{mmHg})$ & 1110 & $63(6)$ & $63(6)$ & $62(6)$ & $62(5)$ & 0.232 \\
\hline Gestational age at birth (days) & 1594 & $281[275,288]$ & $281[274,287]$ & $282[275,287]$ & $282[274,288]$ & 0.724 \\
\hline Child sex $(\%)$ & & & & & & 0.812 \\
\hline Boy & 850 & 53.8 & 54.9 & 51.5 & 53.1 & \\
\hline Girl & 744 & 46.2 & 45.1 & 48.5 & 46.9 & \\
\hline Season of blood sampling (\%) & & & & & & $<0.001$ \\
\hline May-October & 846 & 30.2 & 44.4 & 61.8 & 75.9 & \\
\hline November-April & 748 & 69.9 & 55.6 & 38.2 & 24.1 & \\
\hline $\begin{array}{l}\text { Child age at } 3 \text { years examination } \\
\text { (months) }\end{array}$ & 1203 & $36.1[35.8,36.9]$ & $36.0[35.8,36.5]$ & $36.0[35.8,36.6]$ & $36.0[35.7,36.4]$ & 0.014 \\
\hline $\begin{array}{l}\text { Duration of exclusive breastfeeding } \\
\text { (weeks) }\end{array}$ & 940 & $20[15-24]$ & $20[16-24]$ & $20[16-24]$ & $20[16-24]$ & 0.835 \\
\hline Vitamin D supplementation ( $\mu \mathrm{g} /$ day) & 836 & $3.1[2.4-5.0]$ & $5.0[2.5-5.0]$ & $4.8[2.5-5.0]$ & $5.0[2.5-5.0]$ & $<0.001$ \\
\hline
\end{tabular}

a Mean (s.D.) (all such numbers); ${ }^{b}$ median [Q1, Q3] (all such numbers); *the groups of BMI $<18$ and BMI 18-24.9 were merged because of $N=2$ in BMI $<18$. Significant associations in bold.

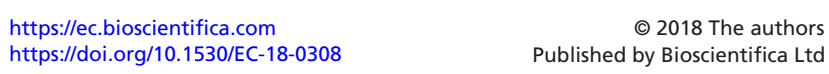


In boys, no consistent crude or adjusted associations were observed between cord s-25OHD and BP at any age (Supplementary Tables 2 and 3). Post hoc testing of an interaction term between child sex and cord s-25OHD did not reach statistical significance in any of the analyses (data not shown).

\section{Pregnancy s-25OHD and blood pressure association}

SBP was inversely associated with s-25OHD in early and late pregnancy in adjusted analyses in 3-year-old girls, whereas DBP was not associated with s-25OHD (Table 4). SBP/DBP at the age of 3.7 and 18.9 months was not associated with maternal s-25OHD sampled in early and late pregnancy (data not shown). Additionally, no association between maternal pregnancy s-25OHD concentrations and BP were seen in boys (data not shown). No post hoc interaction terms between child sex and pregnancy s-25OHD reached statistical significance (data not shown).

\section{Discussion}

In this large Danish prospective cohort study, we found an inverse association between cord s-25OHD and SBP and DBP in 3-year-old girls with evidence of a dose-response relationship. No such consistent associations between s-25OHD and BP were found in boys.
The inverse association between cord s-25OHD and $\mathrm{BP}$ in girls was strongest at 3 years, but significant findings were already detectable at 18.9 months with reduced odds of having SBP >90th percentile with higher cord s-25OHD. Additionally, SBP in girls at three years was inversely associated with maternal s-25OHD in both early and late pregnancy. The strength of the inverse association seemed to increase with gestational age, indicating critical importance of sufficient levels of s-25OHD on SBP especially in late gestation and up to birth.

In concurrence with our study, a large observational study by Williams et al. found an inverse association between maternal s-25OHD in late pregnancy and offspring SBP measured at 9.9 years, however, the association was not present at 15.4 years (14). Moreover, no analyses stratified by offspring sex were performed. Smaller observational studies $(15,16)$, one with univariate analysis only (15) and one exclusively comparing the BP in children of deficient (s-25OHD $<50 \mathrm{nmol} / \mathrm{L}$ ) and nondeficient mothers in adjusted analyses (16), have shown no associations at age 5, 9 and 9.5 years. In agreement with the sex-differential findings from the present study, a Danish cohort study by Rytter et al. found a crude inverse association between maternal s-25OHD concentration during week 30 of gestation and offspring BP at age 20 years in girls only. However, the association did not reach statistically significance in adjusted analyses (17). Another observational study did not find an association between neonatal s-25OHD and $\mathrm{BP}$ at 35 years age

Table 2 Unadjusted associations of cord s-25OHD with systolic and diastolic blood pressure in girls in OCC.

\begin{tabular}{|c|c|c|c|c|c|}
\hline & \multirow[b]{2}{*}{$\mathbf{N}$} & \multicolumn{2}{|c|}{ Continuous cord s-25OHD } & \multicolumn{2}{|c|}{$\begin{array}{c}\text { Cord s-250HD > 50th percentile } \\
\text { (ref. <50th percentile) }\end{array}$} \\
\hline & & $\beta(95 \% \mathrm{Cl})$ & $P$ Value & $\beta(95 \% \mathrm{Cl})$ & $P$ Value \\
\hline \multicolumn{6}{|l|}{ SBP } \\
\hline 3.7 months & 508 & $0.01(-0.04,0.05)$ & 0.854 & $0.23(-1.94,2.41)$ & 0.832 \\
\hline 18.9 months & 341 & $-0.01(-0.06,0.04)$ & 0.776 & $1.03(-1.09,3.14)$ & 0.340 \\
\hline 3 years & 530 & $-0.05(-0.08,-0.02)$ & 0.001 & $-1.84(-3.10,-0.59)$ & 0.004 \\
\hline \multicolumn{6}{|l|}{ DBP } \\
\hline 3.7 months & 508 & $0.003(-0.04,0.04)$ & 0.875 & $-0.40(-2.23,1.44)$ & 0.671 \\
\hline 18.9 months & 341 & $0.02(-0.02,0.06)$ & 0.325 & $1.70(0.07,3.33)$ & 0.041 \\
\hline \multirow[t]{2}{*}{3 years } & 530 & $-0.02(-0.04,0.004)$ & 0.096 & $-1.12(-2.11,-0.12)$ & 0.028 \\
\hline & & OR $(95 \% \mathrm{Cl})$ & $P$ Value & OR $(95 \% \mathrm{Cl})$ & $P$ Value \\
\hline \multicolumn{6}{|c|}{ SBP >90th percentile (ref. SBP $<90$ th p) } \\
\hline 3.7 months & & $1.00(0.99,1.02)$ & 0.880 & $0.85(0.42,1.70)$ & 0.637 \\
\hline 18.9 months & & $0.99(0.97,1.01)$ & 0.354 & $0.88(0.42,1.84)$ & 0.732 \\
\hline 3 years & & $0.97(0.95,0.99)$ & $<0.001$ & $0.44(0.23,0.85)$ & 0.015 \\
\hline \multicolumn{6}{|c|}{ DBP > 90th $p$ (ref. DBP < 90 th $p)$} \\
\hline 3.7 months & & $1.00(0.99,1.02)$ & 0.879 & $0.83(0.44,1.59)$ & 0.581 \\
\hline 18.9 months & & $1.00(0.98,1.02)$ & 0.992 & $1.56(0.67,3.61)$ & 0.301 \\
\hline 3 years & & $0.99(0.97,1.00)$ & 0.082 & $0.71(0.40,1.28)$ & 0.254 \\
\hline
\end{tabular}

Significant associations in bold.

$\mathrm{Cl}$, confidence interval; DBP, diastolic blood pressure; OR, odds ratio; ref., reference; s-25OHD, serum 25-hydroxyvitamin $\mathrm{D}_{2+3}$; SBP, systolic blood pressure.

$$
\begin{array}{lr}
\text { https://ec.bioscientifica.com } & \text { ○ } 2018 \text { The authors } \\
\text { https://doi.org/10.1530/EC-18-0308 } & \text { Published by Bioscientifica Ltd }
\end{array}
$$

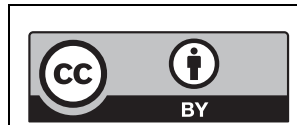


Table 3 Adjusted associations of cord s-25OHD with systolic and diastolic blood pressure in girls in OCC.

\begin{tabular}{|c|c|c|c|c|c|}
\hline & \multirow[b]{2}{*}{$\boldsymbol{N}$} & \multicolumn{2}{|c|}{ Continuous cord s-25OHD } & \multicolumn{2}{|c|}{$\begin{array}{c}\text { Cord s-250HD }>\text { 50th percentile (ref } \\
<50 \text { th percentile) }\end{array}$} \\
\hline & & $\beta(95 \% \mathrm{Cl})$ & $P$ Value & $\beta(95 \% \mathrm{Cl})$ & $P$ Value \\
\hline \multicolumn{6}{|l|}{ SBP } \\
\hline 3.7 months & 376 & $0.01(-0.04,0.07)$ & 0.618 & $0.58(-2.03,3.18)$ & 0.664 \\
\hline 18.9 months & 258 & $-0.02(-0.09,0.04)$ & 0.476 & $-0.72(-3.18,1.73)$ & 0.561 \\
\hline 3 years & 384 & $-0.07(-0.11,-0.03)$ & 0.001 & $-2.47(-4.03,-0.88)$ & 0.002 \\
\hline \multicolumn{6}{|l|}{ DBP } \\
\hline 3.7 months & 376 & $0.013(-0.04,0.06)$ & 0.610 & $-0.14(-2.34,2.06)$ & 0.900 \\
\hline 18.9 months & 258 & $0.005(-0.05,0.06)$ & 0.855 & $0.40(-0.61,1.50)$ & 0.699 \\
\hline \multirow[t]{2}{*}{3 years } & 384 & $-0.04(-0.07,-0.01)$ & 0.016 & $-1.66(-2.91,-0.41)$ & 0.009 \\
\hline & & OR $(95 \% \mathrm{Cl})$ & $P$ Value & OR $(95 \% \mathrm{Cl})$ & $P$ Value \\
\hline \multicolumn{6}{|c|}{ SBP >90th percentile (ref. SBP <90th p) } \\
\hline 3.7 months & & $0.01(0.99,1.03)$ & 0.365 & $1.16(0.48,2.80)$ & 0.742 \\
\hline 18.9 months & & $0.97(0.95,1.00)$ & 0.029 & $0.33(0.11,0.93)$ & 0.036 \\
\hline 3 years & & $0.97(0.95,0.99)$ & 0.004 & $0.36(0.15,0.85)$ & 0.020 \\
\hline \multicolumn{6}{|c|}{ DBP $>90$ th $p$ (ref. DBP $<90$ th $p)$} \\
\hline 3.7 months & & $1.00(0.98,1.02)$ & 0.986 & $0.82(0.37,1.81)$ & 0.626 \\
\hline 18.9 months & & $1.00(0.97,1.02)$ & 0.911 & $1.17(0.42,3.25)$ & 0.760 \\
\hline 3 years & & $0.98(0.96,1.00)$ & 0.045 & $0.58(0.28,1.22)$ & 0.154 \\
\hline
\end{tabular}

All models were stratified by sex and adjusted for maternal educational level, season of birth and child height, weight and age. Significant associations in bold.

$\mathrm{Cl}$, confidence interval; DBP, diastolic blood pressure; OR, odds ratio; ref., reference; s-25OHD, serum 25-hydroxyvitamin $\mathrm{D}_{2+3}$; $\mathrm{SBP}$, systolic blood pressure.

(20), but no investigations of sex-specific patterns were performed regarding BP.

To the best of our knowledge, the association between vitamin D and BP in girls only has not been described previously with the exception of the indications of a possible sex-specific association in Rytter et al. (17). We present no biological explanation for the sex-differential pattern in our study. However, increasing evidence suggests that sex hormones might affect $\mathrm{BP}$ and that oestrogens may be a protective factor potentially via modulation of RAS $(21,22)$. Additionally, animal studies indicate that oestrogen may also have a protective effect on developmental programming of BP in females in young adulthood (23). We may speculate that vitamin $\mathrm{D}$ in pregnancy affects sex hormone patterns in favour of a protective effect on BP in girls via RAS. Sex-specific findings have previously been described regarding to the association between maternal s-25OHD and HDL cholesterol and percentage body fat in boys in the study by Krishnaverni et al. (16). Moreover, Christensen et al. identified an inverse association between late pregnancy and cord s-25OHD and lower leg length in boys (24).

In this study, we observed SBP and DBP lowered with $2.5 \mathrm{mmHg}$ and $1.7 \mathrm{mmHg}$ respectively when s-25OHD levels were above the median concentration in girls aged 3 years. We currently do not know the magnitude of the clinical and public health consequences of such BP differences in childhood, or whether this difference remains later in childhood and adolescence. However, studies show a strong association between childhood BP and BP later in life (3). Further studies into the consequences of childhood BP on cardiac health in later life are needed to fully understand the implications of our findings.

The major strengths of our study include the use of a large population-based birth cohort; longitudinal s-25OHD sampling and detailed anthropometric measures

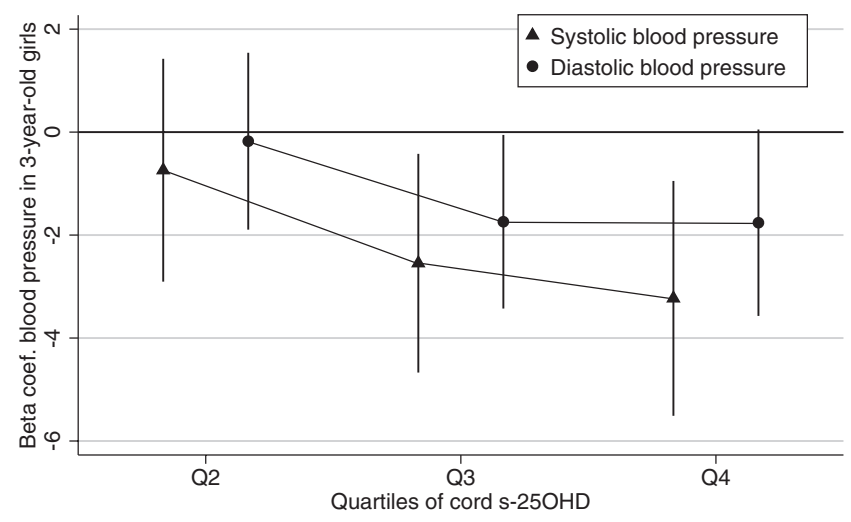

Figure 2

Adjusted associations of s-25OHD divided by quartiles with SBP and DBP in 3-year-old girls from Odense Child Cohort. The multiple linear regression model was stratified by sex and adjusted for maternal educational level, season of birth and child height, weight and age. Reference: Q1. Coef., Coefficient; Q, quartile; s-25OHD, serum 25-hydroxyvitamin $\mathrm{D}_{2+3}$.

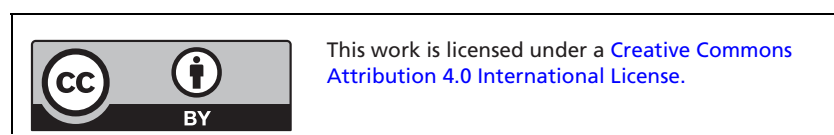


Table 4 Associations of cord s-25OHD and maternal pregnancy s-25OHD levels with systolic and diastolic blood pressure in girls aged 3 years.

\begin{tabular}{|c|c|c|c|}
\hline & & Adjusted model & \\
\hline & $N$ & $\beta(95 \% \mathrm{Cl})$ & $P$-Value \\
\hline \multicolumn{4}{|l|}{ SBP 3 years } \\
\hline $\begin{array}{l}\text { Early pregnancy } \\
\text { s-25OHD }\end{array}$ & 214 & $-0.05(-0.10,-0.003)$ & 0.038 \\
\hline $\begin{array}{l}\text { Late pregnancy } \\
\text { s-25OHD }\end{array}$ & 268 & $-0.06(-0.09,-0.02)$ & 0.001 \\
\hline Cord s-25OHD & 384 & $-0.07(-0.11,-0.03)$ & 0.001 \\
\hline \multicolumn{4}{|l|}{ DBP 3 years } \\
\hline $\begin{array}{l}\text { Early pregnancy } \\
\text { s-25OHD }\end{array}$ & 214 & $-0.01(-0.05,0.03)$ & 0.700 \\
\hline $\begin{array}{l}\text { Late pregnancy } \\
\text { s- } 250 H D\end{array}$ & 268 & $-0.02(-0.05,0.002)$ & 0.066 \\
\hline Cord s-25OHD & 384 & $-0.04(-0.07,-0.01)$ & 0.016 \\
\hline
\end{tabular}

All models were stratified by sex and adjusted for maternal educational level, season of birth and child height, weight and age. Significant associations in bold.

$\mathrm{Cl}$, confidence interval; DBP, diastolic blood pressure; s-25OHD, serum 25-hydroxyvitamin $\mathrm{D}_{2+3}$ i $\mathrm{SBP}$, systolic blood pressure.

by trained study staff blinded for s-25OHD analysis; the use of s-25OHD, which is generally agreed to be the best marker for vitamin D status, with the gold standard LC-MS/ MS method and robust statistical analysis. It is unknown whether the routine s-25OHD cut-offs are applicable in pregnancy and cord blood for non-skeletal health outcomes. Therefore, statistical analyses were performed primary by using median and quartiles analysis, and only secondarily by routine cut-off values.

Limitations included the observational nature of the study, a risk of selection bias, as women included in OCC have higher socio-economic status and are more frequently of ethnic Danish origin compared to the background population (18). Other limitations include utilization of self-reported data and the single measure of BP by Welch Allyn device, which, however, correlates reasonably well with auscultation and is preferred when measuring BP in newborns and infants because of the difficulty of auscultation in this age group (25).

\section{Conclusion}

In this large, Danish cohort, we found an inverse association between cord s-25OHD and BP in 3-year-old girls, but not in boys. Higher vitamin D status in foetal life may modulate BP in young girls.

\section{Supplementary data}

This is linked to the online version of the paper at https://doi.org/10.1530/ EC-18-0308.
Declaration of interest

The authors declare that there is no conflict of interest that could be perceived as prejudicing the impartiality of the research reported.

\section{Funding}

This research did not receive any specific grant from any funding agency in the public, commercial or not-for-profit sector.

\section{Acknowledgement}

The authors thank the cohort staff and families participating in OCC.

\section{References}

1 Kunutsor SK, Burgess S, Munroe PB \& Khan H. Vitamin D and high blood pressure: causal association or epiphenomenon? European Journal of Epidemiology 201429 1-14. (https://doi.org/10.1007/ s10654-013-9874-z)

2 Magnussen CG \& Smith KJ. Pediatric blood pressure and adult preclinical markers of cardiovascular disease. Clinical Medicine Insights: Blood Disorders 20169 1-8.

3 Chen X \& Wang Y. Tracking of blood pressure from childhood to adulthood: a systematic review and meta-regression analysis. Circulation 2008117 3171-3180. (https://doi.org/10.1161/ CIRCULATIONAHA.107.730366)

4 Kunutsor SK, Apekey TA \& Steur M. Vitamin D and risk of future hypertension: meta-analysis of 283,537 participants. European Journal of Epidemiology 201328 205-221. (https://doi.org/10.1007/s10654013-9790-2)

5 Dolinsky DH, Armstrong S, Mangarelli C \& Kemper AR. The association between vitamin $\mathrm{D}$ and cardiometabolic risk factors in children: a systematic review. Clinical Pediatrics 201352 210-223. (https://doi.org/10.1177/0009922812470742)

6 Andersen LB, Przybyl L, Haase N, von Versen-Hoynck F, Qadri F, Jorgensen JS, Sorensen GL, Fruekilde P, Poglitsch M, Szijarto I, et al. Vitamin D depletion aggravates hypertension and target-organ damage. Journal of the American Heart Association 20154 e001417. (https://doi.org/10.1161/JAHA.114.001417)

7 Gezmish O \& Black MJ. Vitamin D deficiency in early life and the potential programming of cardiovascular disease in adulthood. Journal of Cardiovascular Translational Research 20136 588-603. (https://doi.org/10.1007/s12265-013-9475-y)

8 Vimaleswaran KS, Cavadino A, Berry DJ, LifeLines Cohort Study Investigators, Jorde R, Dieffenbach AK, Lu C, Alves AC, Heerspink HJ, Tikkanen E, et al. Association of vitamin D status with arterial blood pressure and hypertension risk: a mendelian randomisation study. Lancet Diabetes and Endocrinology 20142 719-729. (https://doi. org/10.1016/S2213-8587(14)70113-5)

9 Kelishadi R, Ardalan G, Motlagh ME, Shariatinejad K, Heshmat R, Poursafa P, Fakhri M, Tajadini M \& Taslimi M. National report on the association of serum vitamin D with cardiometabolic risk factors in the pediatric population of the Middle East and North Africa (MENA): the CASPIAN-III Study. Nutrition 201430 33-38. (https:// doi.org/10.1016/j.nut.2013.05.018)

10 Christesen HT, Elvander C, Lamont RF \& Jorgensen JS. The impact of vitamin D in pregnancy on extraskeletal health in children: a systematic review. Acta Obstetricia et Gynecologica Scandinavica 2012 91 1368-1380. (https://doi.org/10.1111/aogs.12006)

11 Andersen LB, Abrahamsen B, Dalgard C, Kyhl HB, Beck-Nielsen SS, Frost-Nielsen M, Jorgensen JS, Barington T \& Christesen HT. Parity and tanned white skin as novel predictors of vitamin D status

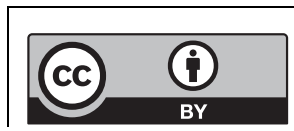

This work is licensed under a Creative Commons Attribution 4.0 International License. 
in early pregnancy: a population-based cohort study. Clinical Endocrinology 201379 333-341. (https://doi.org/10.1111/cen.12147)

12 Harvey NC, Holroyd C, Ntani G, Javaid K, Cooper P, Moon R, Cole Z, Tinati T, Godfrey K, Dennison E, et al. Vitamin D supplementation in pregnancy: a systematic review. Health Technology Assessment 201418 1-190. (https://doi.org/10.3310/hta18450)

13 Tarry-Adkins JL \& Ozanne SE. Mechanisms of early life programming: current knowledge and future directions. American Journal of Clinical Nutrition 201194 1765S-1771S. (https://doi.org/10.3945/ ajcn.110.000620)

14 Williams DM, Fraser A, Fraser WD, Hypponen E, Davey Smith G, Deanfield J, Hingorani A, Sattar N \& Lawlor DA. Associations of maternal 25-hydroxyvitamin D in pregnancy with offspring cardiovascular risk factors in childhood and adolescence: findings from the Avon Longitudinal Study of Parents and Children. Heart 201399 1849-1856. (https://doi.org/10.1136/heartjnl-2013-303678)

15 Gale CR, Robinson SM, Harvey NC, Javaid MK, Jiang B, Martyn CN, Godfrey KM, Cooper C \& Princess Anne Hospital Study Group. Maternal vitamin D status during pregnancy and child outcomes. European Journal of Clinical Nutrition 200862 68-77. (https://doi. org/10.1038/sj.ejcn.1602680)

16 Krishnaveni GV, Veena SR, Winder NR, Hill JC, Noonan K, Boucher BJ, Karat SC \& Fall CH. Maternal vitamin D status during pregnancy and body composition and cardiovascular risk markers in Indian children: the Mysore Parthenon Study. American Journal of Clinical Nutrition 201193 628-635. (https://doi.org/10.3945/ ajcn.110.003921)

17 Rytter D, Bech BH, Halldorsson TI, Henriksen TB, Grandstrom C, Cohen A \& Olsen SF. Maternal vitamin D status at week 30 of gestation and offspring cardio-metabolic health at 20 years: a prospective cohort study over two decades. PLOS ONE 201611 e0164758. (https://doi.org/10.1371/journal.pone.0164758)
18 Kyhl HB, Jensen TK, Barington T, Buhl S, Norberg LA, Jorgensen JS, Jensen DF, Christesen HT, Lamont RF \& Husby S. The Odense Child Cohort: aims, design, and cohort profile. Paediatric and Perinatal Epidemiology 201529 250-258. (https://doi.org/ 10.1111/ppe.12183)

19 Fitzpatrick TB. The validity and practicality of sun-reactive skin types I through VI. Archives of Dermatology 1988124 869-871. (https://doi. org/10.1001/archderm.1988.01670060015008)

20 Tornhammar P, Ueda P, Hult M, Simila H, Eyles D \& Norman M. Season of birth, neonatal vitamin D status, and cardiovascular disease risk at 35 y of age: a cohort study from Sweden. American Journal of Clinical Nutrition 201499 472-478. (https://doi. org/10.3945/ajcn.113.072520)

21 Kuroski de Bold ML. Estrogen, natriuretic peptides and the reninangiotensin system. Cardiovascular Research 199941 524-531. (https://doi.org/10.1016/S0008-6363(98)00324-1)

22 Ojeda NB, Grigore D, Robertson EB \& Alexander BT. Estrogen protects against increased blood pressure in postpubertal female growth restricted offspring. Hypertension 200750 679-685. (https:// doi.org/10.1161/HYPERTENSIONAHA.107.091785)

23 Ojeda NB, Intapad S \& Alexander BT. Sex differences in the developmental programming of hypertension. Acta Physiologica 2014 210 307-316. (https://doi.org/10.1111/apha.12206)

24 Christensen ME, Beck-Nielsen SS, Dalgard C, Larsen SD, Lykkedegn S, Kyhl HB, Husby S \& Christesen HT. A novel inverse association between cord 25-hydroxyvitamin D and leg length in boys up to three years. An Odense Child Cohort study. PLOS ONE 201813 e0198724. (https://doi.org/10.1371/journal.pone.0198724)

25 National High Blood Pressure Education Program Working Group on High Blood Pressure in Children and Adolescents. The fourth report on the diagnosis, evaluation, and treatment of high blood pressure in children and adolescents. Pediatrics $2004114555-576$

Received in final form 26 September 2018

Accepted 4 October 2018

Accepted Preprint published online 4 October 2018

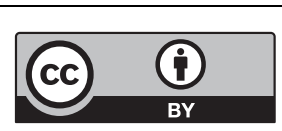

This work is licensed under a Creative Commons Attribution 4.0 International License. 